\title{
XỬ TRÍ THƯƠNG TỒN NGÃ 3 CHỦ CHẬU TRONG GHÉP THẬN: BÁO CÁO 2 TRƯỜnG HỢP VÀ ĐIỂM LẠI Y VĂN
}

\section{TÓM TÁT}

Từ tháng 7/2018 đến tháng 7/2019, chúng tôi thực hiện 85 ca ghép thận, trong đó có 1 bệnh nhân nam 45 tuổi và 1 bệnh nhân nam 58 tuổi đã được làm cầu nối động mạch chủ - động mạch chậu ngoài phải bằng mạch nhân tạo và làm miệng nối động mạch thận - mạch nhân tạo cùng thì. Theo dõi sau 4 và 12 tháng, kết quả phẫu thuật tốt.

Tù khóa: ghép thận, thương tổn ngã 3 chủ chậu, mạch nhân tạo

TREATMENT OF AORTOILIAC DISEASE CONCOMITANT WITH KIDNEY

TRANSPLANTATION: 2 CASES REPORT AND REVIEW THE LITERATURE

\section{SUMMARY}

From 7/2018 to 7/2019, we perform 85 cases of renal transplantation. A 45 year old male patient and a 58 year old male patient were performed aorto- right extenal iliac bypass and renal arteryprosthesis graft anastomosis. Postoperation 4 month and 12 month, 2 patients are stable.

Key words: renal transplantation, aortoiliac disease, vascular prosthesis graft

\section{I. ĐẶT VẤN ĐỀ}

Bệnh thận giai đoạn cuối là một vấn đề sức khỏe chính của nhiều quốc gia trên thế giới. Ghép thận đem lại thời gian sống và chất lượng cuộc sống tốt hơn so với lọc máu chu kỳ. Tuy nhiên trong khi chờ ghép thận, quá trình lọc máu chu kỳ kết hợp với các yếu tố nguy cơ: tăng huyết áp, rối loạn chuyển hóa lipid, đái tháo đường.. làm xuất hiện các thương tổn động mạch vùng chủ chậu. Những bệnh nhân này trước đây được coi như chống chỉ định cho ghép thận. Sau này, nhờ những kết quả rất khả quan của ghép thận mà chỉ định ghép cũng được mở rộng hơn. Khi đó ghép

\author{
Ngô Gia Khánh *, Đồng Minh Hùng *
}

thận ở những bệnh nhân có thương tổn ngã 3 chủ chậu được coi như một thách thức.

\section{II. ĐỐI TƯợNG PHƯƠNG PHÁP} NGHIÊN CÚU

Từ tháng 7/2018 đến tháng 7/2019, tại $\mathrm{BV}$ Bạch Mai thực hiện 85 ca ghép thận, trong đó có 2 trường hợp vôi hóa nặng động mạch chậu.

\section{KẾT QUẢ}

Trường hợp 1: BN nam, 45 tuổi, bệnh thận giai đoạn cuối, lọc máu chu kỳ 4 năm, rối loạn lipid máu (giảm HDL-C). Siêu âm ĐM chủ chậu trước mổ: có vôi hóa rải rác ĐM chủ chậu nhưng không gây hẹp lòng mạch. Quá trình phẫu thuật: nối TM thận - TM chậu ngoài, ĐM thận ghép - ĐM chậu ngoài kiểu tận-bên (thời gian làm miệng nối 17 phút). Sau thả kẹp mạch máu, thận hồng, căng, có nước tiểu sau 10 giây. Sau khi cắm niệu quản vào bàng quang(thời gian thực hiện 24 phút), kiểm tra lại thấy thận xẹp, tím hơn, không có thêm nước tiểu. Bộc lộ ĐM kiểm tra, ĐM chậu chung vôi hóa nhiều, dòng chảy yếu do sập mảng xơ vữa. Bệnh nhân được làm cầu nối ĐM chủ ĐM chậu ngoài phải bằng mạch nhân tạo số 8 , cắt rời miệng nối ĐM thận - ĐM chậu ngoài và nối ĐM thận vào mạch nhân tạo. Không sử dụng dung dịch bảo quản tạng, thời gian làm các miệng nối 32 phút. Sau thả kẹp, tưới máu thận tốt. Không sử dụng chống đông trong và sau mổ. Kết quả sau mổ: creatinin máu sau mổ ngày thứ 2 là $125 \mathrm{mcmol} / 1$. Siêu âm ĐM thận ngay sau mổ và trước khi ra viện: tưới máu thận bình thường, không thấy hẹp miệng nối. Bệnh nhân ra viện sau mổ 10 ngày. Hiện tại sau mổ 12 tháng, kết quả ghép thận tốt.

\footnotetext{
* Bệnh viện Bạch Mai

Người chịu trách nhiệm khoa học: BS Ngô Gia Khánh

Ngày nhận bài: 01/11/2019 - Ngày Cho Phép Đăng: 20/12/2019

Phản Biện Khoa học: PGS.TS. Đặng Ngọc Hùng GS.TS. Lê Ngoc Thành
} 


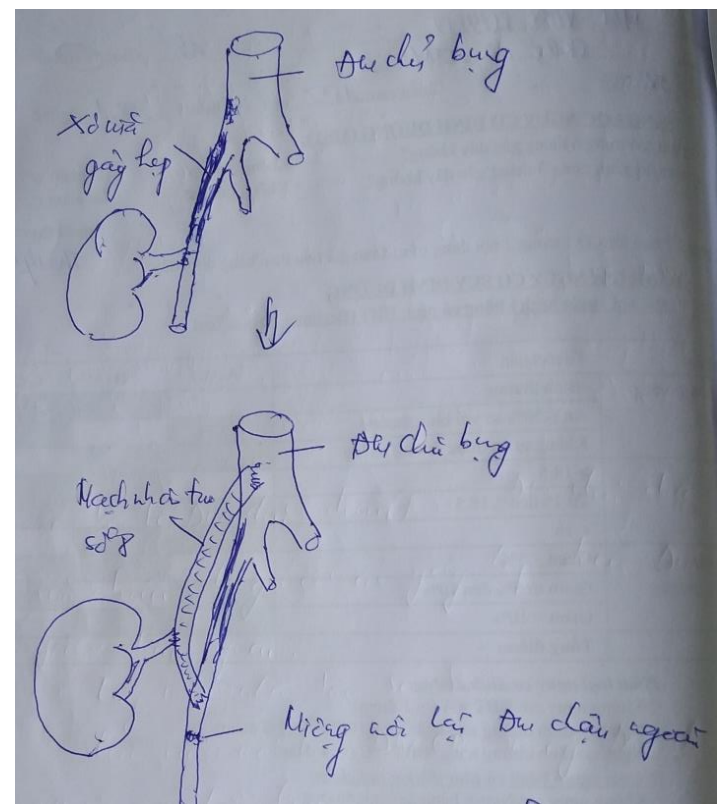

Hình 1: Lươc đồ phẫu thuật trường hợp 1

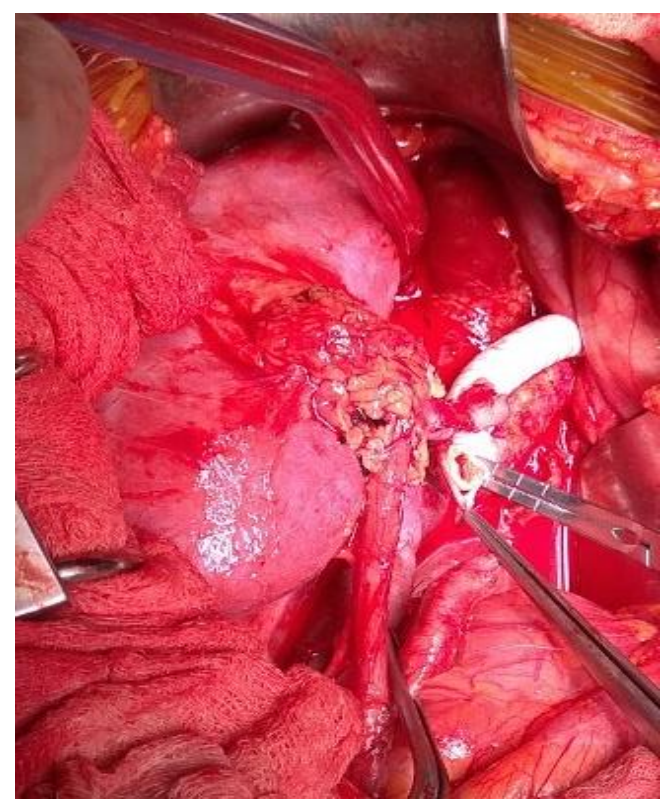

Hình 2: Hình ảnh trong mổ (miệng nối ĐM thận ghép vào mạch nhân tạo)

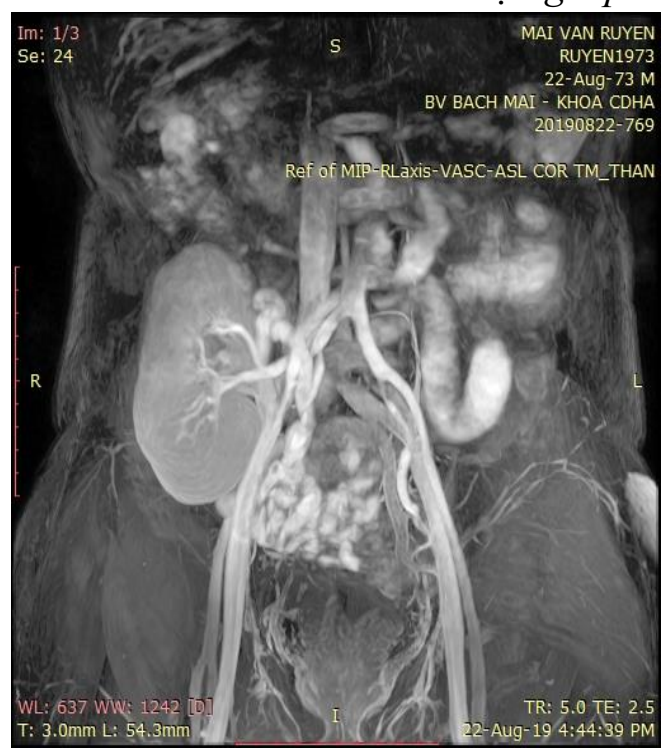

Hình 3: Phim chup MRI truờng hơp 1

Trường hợp 2: BN nam 58 tuổi, đái tháo đường 7 năm, rối loạn lipid máu (tăng triglyceride, giảm HDL-C), sỏi niệu quản 2 bên đã mổ cách 10 năm và 7 năm, suy thận mạn 4 năm, lọc máu chu kỳ 2 tháng trước ghép thận. Siêu âm ĐM chủ chậu trước mổ: có vôi hóa rải rác ĐM chủ chậu nhưng không gây hẹp lòng mạch. Chụp MSCT mạch chủ chậu trước mổ: vôi hóa ĐM chủ chậu gây hẹp $20 \%$ ĐM chậu chung 2 bên. Quá trình phẫu thuật: $\mathrm{BN}$ được làm cầu nối $Đ M$ chủ - ĐM chậu ngoài bằng mạch nhân tạo số 8 . Làm 2 miệng nối TM thận - TM chậu ngoài, 3 miệng nối ĐM thận - mạch nhân tạo. Thời gian thiếu máu ấm 44 phút. Sau thả kẹp mạch máu, thận hồng, căng, có nước tiểu sau 30 giây. Dùng Heparin và aspirin sau mổ. Kết quả sau mổ: creatinin máu ngày t2 sau mổ là $115 \mathrm{mcmol} / \mathrm{l}$. Siêu âm ĐM thận ngay sau mổ và trước khi ra viện: tưới máu thận bình thường, không thấy hẹp miệng nối. Bệnh nhân ra viện sau mổ 9 ngày. Hiện tại sau mổ 4 tháng, kết quả ghép thận tốt. 


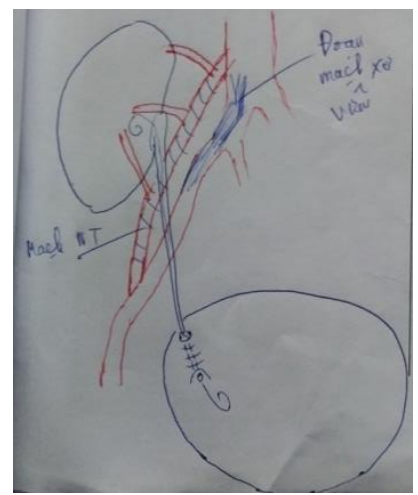

Hình 4: Lươc đồ phẫu thuật trường hợp 2

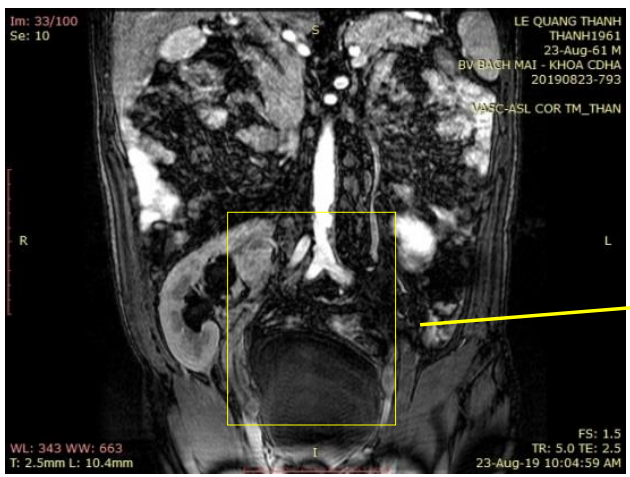

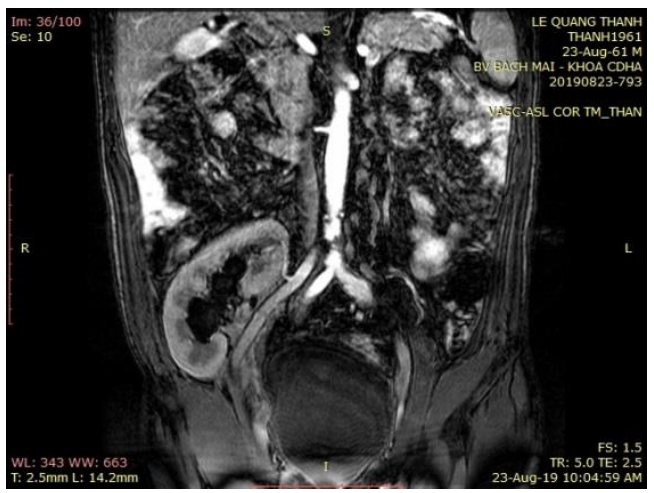

Hình 5: Phim chup MRI động mạch thận ghép

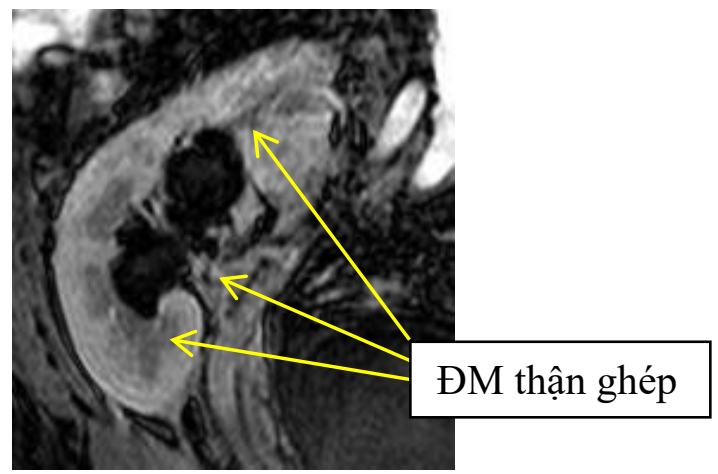

\section{BÀN LUẬN}

Hình 6: Phim chụp MRI động mạch thận ghép

Trường hợp ghép ĐM thận vào mạch nhân tạo được mô tả lần đầu bởi Sterioff và cộng sự năm 1974 [1]. Sau đó các trường hợp tương tự cũng được báo cáo dưới dạng ca lâm sang hoặc chùm ca lâm sàng.

\section{Bảng 1. Tuổi trung bình trong các nghiên cứu}

\begin{tabular}{llcc}
\hline & Tác giả & N & Tuổi trung bình \\
\hline 1 & Han, D. J (2014) & 27 & $51.4+\_9.1$ \\
2 & Matteo Tozzi (2013) & 21 & $54+\_9$ \\
3 & Patrono, D (2013) & 27 & 56 \\
4 & Z.Galazka (2011) & 12 & $45-68$ \\
5 & Meritxell Davins (2009) & 11 & 57.8 \\
6 & Tsivian M (2009) & 30 & $55(43-65)$ \\
7 & I. Matia (2008) & 14 & $53(32-67)$ \\
8 & Özçelik, A (2007) & 11 & $58(37-82)$ \\
9 & Pittaluga P (1998) & 83 & 49.9 \\
10 & Brekke IB (1993) & 26 & $60(33-74)$ \\
\hline
\end{tabular}


Do số lượng $\mathrm{BN}$ trong các nghiên cứu thường là không lớn, trải dài qua nhiều năm nên các tác giả không đi sâu vào phân tích các yếu tố nguy cơ, tuy nhiên đều có điểm chung là tuổi cao, có thời gian lọc máu chu kỳ kéo dài, có kèm các bệnh lý gây vữa xơ mạch máu như đái tháo đường, rối loạn lipid máu... Brekke IB [3] nghiên cứu trên $1400 \mathrm{BN}$ chờ ghép thận trong 7 năm (1984-1991) đã đưa ra khuyến cao nên chụp mạch kiểm tra ở những $\mathrm{BN}$ chờ ghép trên 40 tuổi. Chúng tôi gặp $2 \mathrm{BN}$ có tuổi là 45 và 58 tuổi, trong đó $1 \mathrm{BN}$ có rối loạn lipid máu, $1 \mathrm{BN}$ có cả đái tháo đường và rối loạn lipid máu.

Khảo sát mạch máu chủ chậu trước khi ghép thận là thăm dò thường quy. Trong đó chụp mạch máu là tiêu chuẩn vàng dùng để đánh giá các tắc nghẽn mạch chủ chậu [2]. Tuy nhiên thăm dò này có tính xâm lấn và chi phí cao. Vai trò của siêu âm mạch máu chủ chậu còn nhiều bàn cãi, với độ nhạy 91\% và độ đặc hiệu 93\% [3] [4], so với độ nhạy 96\% và độ đặc hiệu 97\% của MSCT [5] [6]. Phim chụp MSCT ghi nhận thông tin một cách khách quan và chi tiết hơn, đặc biệt trên mặt cắt Axial, về kích thước mạch chủ chậu (mức độ giãn) hoặc mức độ hẹp cũng như tình trạng vôi hóa.

Chỉ định điều trị sửa chữa (can thiệp nội mạch/phẫu thuật) đối với phồng ĐM chủ bụng đã được khuyến cáo từ lâu. Bảng 2 so sánh khuyến cáo điều trị sửa chữa phồng ĐM chủ bụng của Hoa Kỳ, Châu Âu và Nhật Bản. Với thương tổn dạng hẹp, vôi hóa ngã 3 chủ chậu được phân loại theo TASC. Mức độ TASC $\mathrm{A}$ và TASC $\mathrm{B}$ được khuyến cáo can thiệp nội mạch, TASC $\mathrm{C}$ và TASC D được khuyến cáo lựa chọn phẫu thuật.

Bảng 2. Tóm tắt khuyến cáo điều trị sửa chữa với phồng ĐMC bụng [13]

\begin{tabular}{|c|c|c|c|}
\hline Khuyến cáo & ACCF-PAD 2013 & JCS-AD 2011 & ESC-AD 2014 \\
\hline $\begin{array}{l}\text { Chỉ định sửa chữa khi phồng ĐMC bụng không } \\
\text { triệu chứng, có kích thước ĐMC lớn nhất }\end{array}$ & $\geq 5.5 \mathrm{~cm}$ & $\begin{array}{l}\geq 5.5 \mathrm{~cm}(\mathrm{nam}) \\
\geq 5 \mathrm{~cm} \text { (nữ) }\end{array}$ & $\geq 5.5 \mathrm{~cm}$ \\
\hline $\begin{array}{l}\text { Cân nhắc sửa chữa khi phồng ĐMC bụng } \\
\text { không triệu chứng có kích thước ĐMC lớn } \\
\text { nhất }\end{array}$ & $5-5.4 \mathrm{~cm}$ & $\begin{array}{l}5-5.4 \mathrm{~cm} \\
4-5 \mathrm{~cm} \text { (nguy cơ } \\
\text { phẫu thuật thấp) }\end{array}$ & \\
\hline $\begin{array}{l}\text { Chỉ định sửa chữa phồng ĐMC bụng không } \\
\text { triệu chứng khi kích thước tăng lên }\end{array}$ & & $>0.5 \mathrm{~cm} / 6$ tháng & $>1 \mathrm{~cm} / 1$ năm \\
\hline $\begin{array}{l}\text { Không khuyến cáo sửa chữa với phồng ĐMC } \\
\text { bụng không triệu chứng có kích thước }\end{array}$ & $\begin{array}{l}<5 \mathrm{~cm}(\text { nam }) \\
<4.5 \mathrm{~cm}(\text { nữ) }\end{array}$ & $<4 \mathrm{~cm}$ & \\
\hline
\end{tabular}

Tuy nhiên với nhóm bệnh nhân ghép thận thì chưa có khuyến cáo cụ thể. Bảng 3 đưa ra tóm tắt lựa chọn thời điểm (trước hay cùng thì ghép thận) cũng như giải pháp cho các thương tổn vùng ngã 3 chủ chậu ở BN ghép thận qua một số nghiên cứu. 
Bảng 3. Sửa chữa thương tổn ngã 3 chủ chậu: lựa chọn giải pháp và thời điểm

\begin{tabular}{|c|c|c|c|c|c|}
\hline & Tác giả & & c ghép thận & Cù & g thì ghép thận \\
\hline 1 & Han, D. J & & & 27 & AOD (TASC A \& B, AS) \\
\hline & (2014) [14] & & & & > 25 bóc nội mạc \\
\hline & $n=27$ & & & & $>2$ PT bắc cầu \\
\hline 2 & Matteo Tozzi & 3 & AAA $(>50 \mathrm{~mm})$ & 18 & $1 \mathrm{AAA}(>45 \mathrm{~mm})$ \\
\hline & $(2013)[12]$ & & $>3$ can thiệp nội mạch & & > 1 PT thay đoạn mạch \\
\hline & $n=21$ & & $>13 \pm 9$ tháng & & 17 AOD (TASC C \& D, AS) \\
\hline & & & & & > 15 bóc nội mạc \\
\hline & & & & & $>2$ bắc cầu \\
\hline 3 & Patrono, D & 22 & AAA+AOD & 2 & AOD + phình ĐM thận ghép \\
\hline & (2013) [15] & & $>$ PT thay đoạn mạch & & $>$ PT thay đoạn mạch \\
\hline & $n=24$ & & $>16.5$ tháng & & \\
\hline 4 & Z.Galazka & 12 & AOD & & \\
\hline & $(2011)[16]$ & & $>$ PT bắc cầu & & \\
\hline & $\mathrm{n}=12$ & & $>11$ tháng (2-25 tháng) & & \\
\hline 5 & Tsivian M & & & 30 & 11 AAA/CIAA \\
\hline & (2009) [7] & & & & $>4$ can thiệp nội mạch \\
\hline & $\mathrm{n}=30$ & & & & > 7 PT thay đoạn mạch \\
\hline & & & & & 19 AOD \\
\hline & & & & & > 15 bóc nội mạc \\
\hline & & & & & > 4 PT bắc cầu \\
\hline 6 & I. Matia & & & 14 & 6 АAA $(45-65 \mathrm{~mm})+8$ AOD \\
\hline & $(2008)[10]$ & & & & > PT thay đoạn mạch \\
\hline & $\mathrm{n}=14$ & & & & \\
\hline 7 & Özçelik, A & & & 11 & AOD \\
\hline & (2007) [17] & & & & $>$ PT bắc cầu \\
\hline & $\mathrm{n}=11$ & & & & \\
\hline 8 & Brekke IB & 26 & 15 AAA & & \\
\hline & (1993) [3] & & $>$ PT thay đoạn mạch & & \\
\hline & $n=26$ & & $11 \mathrm{AOD}$ & & \\
\hline & & & > 1 bóc nội mạc & & \\
\hline & & & $>10$ PT bắc cầu & & \\
\hline & & & 16 tháng (4-45 tháng) & & \\
\hline
\end{tabular}

AAA: phồng ĐM chủ bụng, AOD: hẹp tắc ngã 3 chủ chậu, CIAA: phồng ĐM chậu chung AS: không triệu chúng 
Các tác giả đều chỉ định điều trị sửa chữa với phồng $Đ M$ chủ bụng khi kích thước $\geq 45 \mathrm{~mm}$. Giải pháp lựa chọn có thể là can thiệp nội mạch hoặc phẫu thuật thay đoạn mạch. Phần lớn các tác giả lựa chọn giải pháp phẫu thuật. Matteo Tozzi (2013) [12] chỉ định can thiệp đặt stent cho 3 BN phồng ĐM chủ bụng, kích thước $>50 \mathrm{~mm}$ do lo ngại nguy cơ vỡ phồng trong khi chờ ghép thận. Hơn nữa can thiệp đặt stent có ưu thế hơn phẫu thuật trong những trường hợp nguy cơ cao (ít tai biến, tránh được khó khăn cho cuộc mổ ghép thận do phải mổ lại). Cũng có tác giả chủ động điều trị phồng $\mathrm{ĐM}$ chủ bụng khi đường kính $>4 \mathrm{~cm}$ cùng thì với ghép thận do lo ngại nguy cơ phải sửa chữa sau này [11].

Với thương tổn hẹp/vôi hóa ngã 3 chủ chậu, các tác giả đều lựa chọn giải pháp phẫu thuật (bóc nội mạc hoặc $\mathrm{PT}$ bắc cầu). Các $\mathrm{BN}$ trong nghiên cứu của Matteo Tozzi (2013) [12] và Han, D. J (2014) [14] có mức độ thương tổn khác nhau, nhưng đều không có triệu chứng lâm sàng. Han, D. J (2014) [14] cũng nhấn mạnh trong nghiên cứu của mình là không nên chỉ định ghép thận cho những $\mathrm{BN}$ có thương tổn hẹp/vôi hóa nặng vùng ngã 3 chủ chậu (TASC C/TASC D và có triệu chứng lâm sàng).
Chúng tôi gặp 2 trường hợp có hẹp ngã 3 chủ chậu khi ghép thận, với phân loại TASC A, và đều được lựa chọn phẫu thuật bắc cầu thay vì can thiệp nội mạch. Một trường hợp do chúng tôi chỉ xác định được thương tổn hẹp ĐM chậu trong khi ghép thận. Một trường hợp xác định có hẹp ĐM chậu chung 2 bên trước ghép thận, mức độ hẹp ít (20\%), không làm thay đổi dòng chảy (xác định trên siêu âm Doppler). Tuy nhiên do lo ngại mức độ hẹp sẽ tăng dần lên, ảnh hưởng đến kết quả ghép thận về lâu dài, cũng như không thấy các tác giả trên thế giới báo cáo về can thiệp nội mạch cho các trường hợp tương tự nên chúng tôi quyết định bắc cầu qua chỗ hẹp và ghép thận cùng thì.

Nhiều tác giả ưu tiên lựa chọn phẫu thuật 2 giai đoạn (xử lý thương tổn ngã 3 chủ chậu trước, sau đó mới ghép thận) do lo ngại nguy cơ nhiễm trùng. Cũng có nhiều tác giả quyết định ghép thận và xử lý thương tổn ngã 3 chủ chậu cùng thì. Trong trường hợp phẫu thuật 2 giai đoạn, thời gian giữa xử lý thương tổn ngã 3 chủ chậu và ghép thận là bao lâu cũng rất khác nhau giữa các tác giả, trong đó $\mathrm{BN}$ ngắn nhất trong nghiên cứu của Z.Galazka (2011) [16] là 2 tháng. Một số tác giả khác khuyến cáo là thời gian tối thiểu là 6 tuần [9], [10].

Bảng 4. Tỷ lệ biến chứng và sống sót của thận ghép qua các nghiên cứu

\begin{tabular}{|c|c|c|c|c|c|c|c|c|}
\hline & Tác giả & $\mathbf{N}$ & $\begin{array}{l}\text { Loại } \\
\text { mạch sử } \\
\text { dụng }\end{array}$ & $\begin{array}{l}\text { Chống đông } \\
\text { sau mổ }\end{array}$ & $\begin{array}{l}\text { Thời gian } \\
\text { theo dõi }\end{array}$ & $\begin{array}{l}\text { Tỷ lệ } \\
\text { nhiễm } \\
\text { trùng } \\
\text { cầu nối }\end{array}$ & $\begin{array}{l}\text { Hỏng thận } \\
\text { ghép do } \\
\text { nguyên } \\
\text { nhân mạch } \\
\text { máu }\end{array}$ & $\begin{array}{l}\text { Tỷ lệ } \\
\text { sống của } \\
\text { thận } \\
\text { ghép * }\end{array}$ \\
\hline \multirow[t]{2}{*}{1} & $\begin{array}{l}\text { Han, D. J } \\
\text { (2014) [14] }\end{array}$ & 2 & $\begin{array}{l}\text { Mạch } \\
\text { nhân tạo }\end{array}$ & - & $35.9 \pm 21.6$ & $0 \%$ & $0 \%$ & $\begin{array}{l}1 \mathrm{y}: 96.3 \% \\
3 y: 96.3 \%\end{array}$ \\
\hline & & & & & & & & $5 y: 86.7 \%$ \\
\hline
\end{tabular}




\begin{tabular}{|c|c|c|c|c|c|c|c|c|}
\hline & Tác giả & $\mathbf{N}$ & $\begin{array}{l}\text { Loại } \\
\text { mạch sử } \\
\text { dụng }\end{array}$ & $\begin{array}{l}\text { Chống đông } \\
\text { sau mổ }\end{array}$ & $\begin{array}{l}\text { Thời gian } \\
\text { theo dõi }\end{array}$ & $\begin{array}{l}\text { Tỷ lệ } \\
\text { nhiễm } \\
\text { trùng } \\
\text { cầu nối }\end{array}$ & $\begin{array}{l}\text { Hỏng thận } \\
\text { ghép do } \\
\text { nguyên } \\
\text { nhân mạch } \\
\text { máu }\end{array}$ & $\begin{array}{l}\text { Tỷ lệ } \\
\text { sống của } \\
\text { thận } \\
\text { ghép * }\end{array}$ \\
\hline 2 & $\begin{array}{l}\text { Matteo } \\
\text { Tozzi } \\
(2013)[12]\end{array}$ & 3 & $\begin{array}{l}\text { Mạch } \\
\text { nhân tạo }\end{array}$ & $\begin{array}{l}\text { Enoxaparin x } 1 \\
\text { tháng } \\
(\mathrm{GFR}<30 \mathrm{ml} / \mathrm{ph}: \\
2000 \mathrm{UI} \\
\text { GFR >30ml/ph : } \\
4000 \mathrm{UI}) \\
+\quad \text { clopidogrel } \\
75 \mathrm{mg}\end{array}$ & 14 tháng & $0 \%$ & $0 \%$ & $1 y: 100 \%$ \\
\hline 3 & $\begin{array}{l}\text { Patrono D } \\
(2013)[15]\end{array}$ & 24 & $\begin{array}{l}\text { Mạch } \\
\text { nhân tạo }\end{array}$ & $\begin{array}{l}\text { LMWH + } \\
\text { acetylsalicylic } \\
100 \mathrm{mg}\end{array}$ & $\begin{array}{l}53 \text { tháng } \\
(1-126)\end{array}$ & $0 \%$ & $\begin{array}{l}1 / 24 \\
(4.17 \%)\end{array}$ & $5 y: 74 \%$ \\
\hline 4 & $\begin{array}{l}\text { Z.Galazka } \\
(2011)[16]\end{array}$ & 8 & $\begin{array}{l}\text { Mạch } \\
\text { nhân tạo }\end{array}$ & - & 46 tháng & $0 \%$ & $0 \%$ & - \\
\hline 5 & $\begin{array}{l}\text { I. Matia } \\
(2008)[10]\end{array}$ & 14 & $\begin{array}{l}\text { Mạch } \\
\text { đồng loài }\end{array}$ & acetylsalicylic & $\begin{array}{l}55.5 \text { tháng } \\
(1-116)\end{array}$ & $0 \%$ & $0 \%$ & $78.6 \%$ \\
\hline 6 & $\begin{array}{l}\text { Özçelik, A } \\
\text { (2007)[17] }\end{array}$ & 11 & $\begin{array}{l}\text { Mạch } \\
\text { nhân tạo }\end{array}$ & - & 6 tháng & $0 \%$ & $\begin{array}{l}2 / 11 \\
(18.2 \%)\end{array}$ & $\begin{array}{l}8 / 11 \\
(72.7 \%)\end{array}$ \\
\hline 7 & $\begin{array}{l}\text { Brekke IB } \\
(1993)[3]\end{array}$ & 16 & $\begin{array}{l}\text { Mạch } \\
\text { nhân tạo }\end{array}$ & - & $\begin{array}{l}3-60 \\
\text { tháng }\end{array}$ & $0 \%$ & $0 \%$ & $\begin{array}{l}13 / 16 \\
(81.3 \%)\end{array}$ \\
\hline
\end{tabular}

(*) được đánh giá chung trên tất cả các BN trong nghiên cứu

(3): 1 TH tắc cầu nối sau mổ 1 ngày do sập mảng xo vĩua

(6): 1 BN thải ghép không do mạch máu, 1 BN tắc cầu nối, 1 TH không tiến hành ghép thận do đánh giá ĐM chậu không đáp úng cho thận ghép

(7): 1 BN tử vong sau mổ 1 tuần do nhồi máu co tim, 2 BN thải ghép không do mạch máu 
Mặc dù lợi ích của đoạn mạch ghép đồng loài trong điều trị các tổn thương nhiễm trùng mạch máu đã được nghiên cứu và chứng minh từ lâu, nhưng đa phần các tác giả vẫn lựa chọn mạch nhân tạo để xử lý thương tổn ngã 3 chủ chậu khi ghép thận. Một trong các lý do được đưa ra là sự không phổ biến của đoạn mạch ghép đồng loài. Trong các nghiên cứu cũng không báo cáo trường hợp nào nhiễm trùng liên qua đến mạch nhân tạo. Patrono D (2013) [15] báo cáo $1 \mathrm{TH}$ tắc cầu nối ngay sau mổ 1 ngày do sập mảng xơ vữa tại

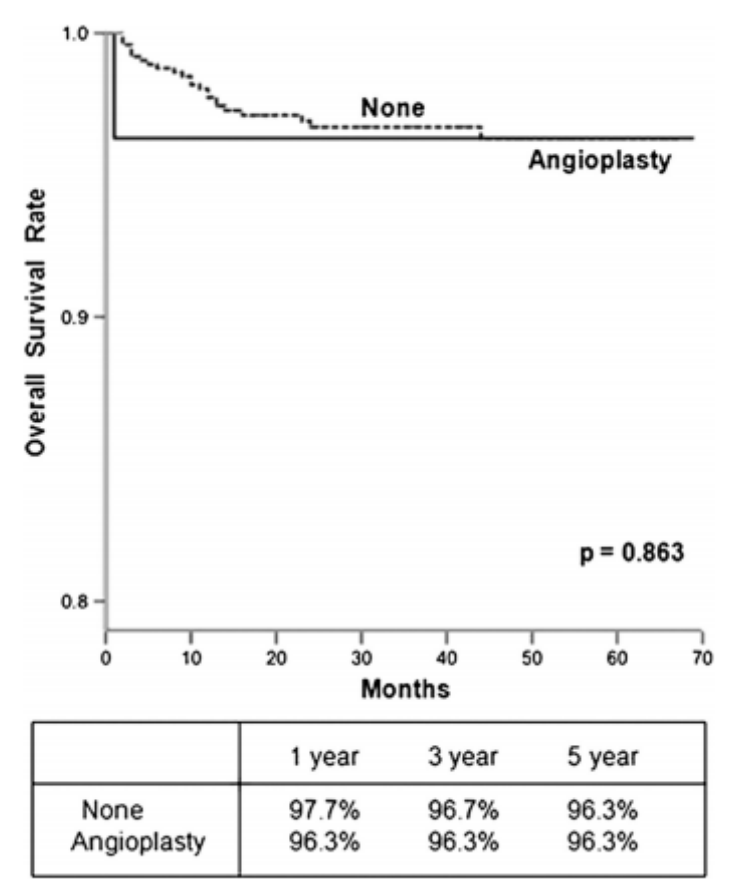

Tỷ lệ sống của 2 nhóm $B N$

\section{KẾT LUẬN}

Kết hợp xử lý thương tổn ngã 3 chủ chậu và ghép thận có thể thực hiện an toàn, hiệu quả ở các trung tâm ghép tạng có phẫu thuật viên kinh nghiệm.

Sử dụng mạch nhân tạo không hoàn toàn chống chỉ định ở bệnh nhân ghép thận.

Kết quả phẫu thuật ngắn và trung hạn đều được báo cáo tốt, tuy nhiên các nghiên cứu đều cho rằng cần theo dõi xa hơn để có thể đưa ra được kết luận. miệng nối, Özçelik, A (2007) [17] báo cáo 1 TH tắc cầu nối và $1 \mathrm{TH}$ không tiến hành ghép do khảo sát ĐM chậu không đủ an toàn để ghép thận. Chúng tôi có $2 \mathrm{TH}$ sử dụng mạch nhân tạo, trong thời gian theo dõi (4 tháng và 12 tháng) chưa ghi nhận các biến chứng liên quan đến mạch máu.

Nghiên cứu của Han, D. J (2014) [14] so sánh giữa $721 \mathrm{BN}$ ghép thận đơn thuần và $27 \mathrm{BN}$ ghép thận có kèm xử lý thương tổn ngã 3 chủ chậu cho thấy không có sự khác biệt về tỷ lệ sống của $\mathrm{BN}$ và của thận ghép giữa 2 nhóm.

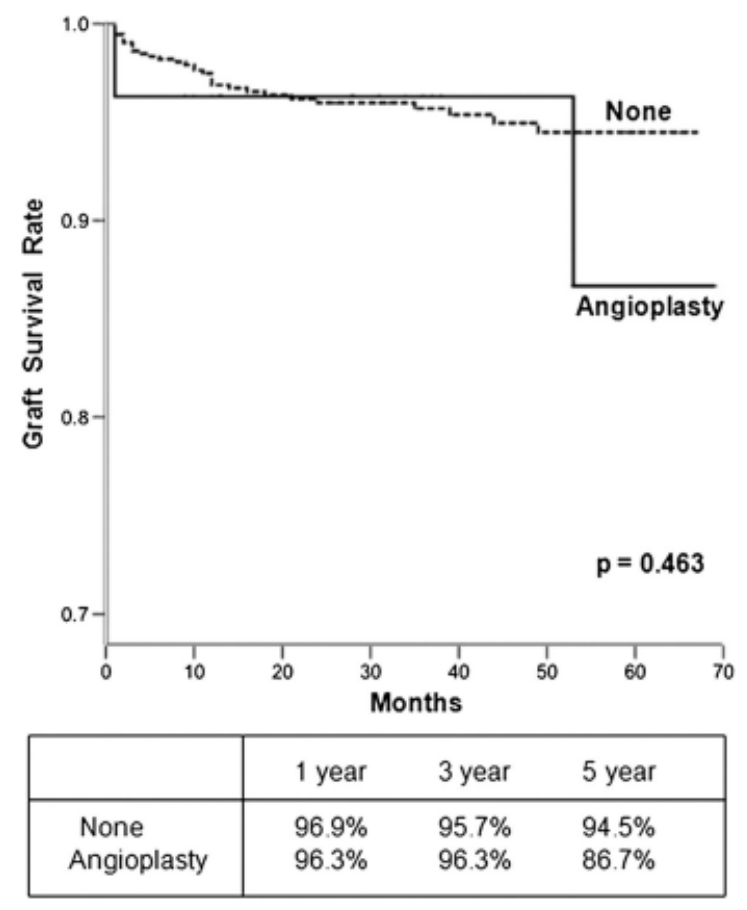

Tỷ lệ sống của thận ghép trong 2 nhóm $B N$

\section{TÀI LIỆU THAM KHẢO}

1. Sterioff S, Zachary JB, Williams GM. Dacron vascular grafts in renal transplant patients. Am J Surg 1974; 127(5): 525-8.

2. Schindler N, Calligaro KD, Lombardi J et al. Has arteriography gotten a bad name? Current accuracy and morbidity of diagnostic contrast angiography for aortoiliac and lower extremity arterial disease. Ann Vasc Surg 2001;15(4):417-20. 
3. Brekke IB, Lien B, Sødal G, et al. Aortoiliac reconstruction in preparation for renal transplantation. Transpl Int 1993;6(3):161-3

4. Currie IC, Jones AJ, Wakeley CJ, et al. Non-invasive aortoiliac assessment. Eur J Vasc Endovasc Surg 1995;9(1):248.

5. Willman JK, Baumert B, Schertler T, et al. Aortoiliac and lower extremity arteries assessed with 16-detector row CT angiography: prospective comparison with digital subtraction angiography. Radiology 2005;236(3):1083-93.

6. Tins B, Oxtoby J, Patel S. Comparison of CT angiography with conventional arterial angiography in aortoiliac occlusive disease. $\mathrm{Br} \mathbf{J}$ Radiol 2001;74(879):219-25.

7. Tsivian M, Neri F, Nardo B, et al. Aortoiliac surgery concomitant with kidney transplantation: a single center experience. Clin Transplant 2009; 23(2): 164-7.

8. Pittaluga $\mathrm{P}$, Hassen-Khodja R, Cassuto-Viguier E, et al. Aortoiliac reconstruction and kidney transplantation: A multicenter study. Ann Vasc Surg 1998; 12(6): 529-36

9. Gouny P, Lenot B, Decaix B, et al. Aortoiliac surgery and kidney transplantation. Ann Vasc Surg 1991; 5(1): 26-31.

10. Matia I, Adamec M, Varga M,et al. Aortoiliac reconstruction with allograft and kidney transplantation as a one-stage procedure: Long term results. Eur J Vasc Endovasc Surg 2008; 35(3): 353-7
11. Aleksandar Tomić et al. Aortobifemoral reconstruction and renal transplantation in a patient with abdominal aortic aneurysm and occlusion of iliac arteries: A case report. Vojnosanit Pregl 2017; 74(1): 81-84

12. Matteo Tozzi et al. Treatment of aortoiliac occlusive or dilatative disease concomitant with kidney transplantation: how and when? International Journal of Surgery (2013) 11(S1), S115-S119

13. Jose Rozado et al, Comparing American, European and Asian practice guidelines for aortic diseases, Journal of Thoracic Disease, 2017;9(Suppl 6):S551-S560

14. Duck Jong Han et al, Effects of Simultaneous Iliac Artery Angioplasty on Graft and Patient Survival After Living-Donor Kidney Transplantation, Transplantation 2014;97: 826Y831

15. Damiano Patrono et al, Renal Allograft Implantation on Prosthetic Vascular Grafts: Short- and Long-term Results, World J Surg (2013) 37:1727-1734

16. Z. Galazka, Is Severe Atherosclerosis in the Aortoiliac Region a Contraindication for Kidney Transplantation?, Transplantation Proceedings, 43, 2908-2910 (2011)

17. A. Özçelik, Results of Kidney Transplantation With Simultaneous Implantation of Vascular Graft, Transplantation Proceedings, 39, 509-510 (2007). 